\title{
Pedagogical in-Service Courses and Novice Teachers' Professional Development
}

\author{
Mohammad Bshoti, Tareq Murad, Nabil Assadi \\ Department of English, Sakhnin Academic College for teacher Education, Sakhnin, 2173, Israel
}

\begin{abstract}
Current study aims to investigate the effect of in-service training courses on novice teachers' professional development. Moreover, the study seeks to examine the types of in-service courses that novice teachers need. The study population is 30 English high school teachers with teaching certificates in the southern district of Israel. The instrument of the study is an online questionnaire with additional open-ended questions. Study findings showed that $47 \%$ of the participants prefer courses in social interaction and educational knowledge. However, few participants showed an interest in self-esteem related courses. The researcher advises novice teachers to priorities their needs in social interaction and educational knowledge courses in order to steadily develop professionally. Moreover, further studies need to be explored in order to examine the effect of pedagogical in-service training courses on veteran teachers' professional development and compare the data between two studies.
\end{abstract}

Keywords - Novice Teachers, Professional development, In-service courses, High school English.

\section{Introduction}

In-service education courses are designed to develop, improve, and update the knowledge and practice for teachers. According to [2] and [10] there are eleven different types of the courses.

DOI: $10.18421 /$ SAR44-06

https://doi.org/10.18421/SAR44-06

Corresponding author: Nabil Assadi., Department of English, Sakhnin Academic College for teacher Education, Sakhnin, 2173, Israel

Email: nabilgood1@gmail.com

Received: 07 September 2021.

Revised: 17 December 2021.

Accepted: 21 December 2021.

Published: 27 December 2021.

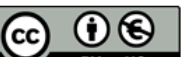

(C) 2021 Mohammad Bshoti, Tareq Murad \& Nabil Assadi; published by UIKTEN. This work is licensed under the CC BY-NC 4.0.

The article is published with Open Access at www.sarjournal.com
Teachers do not necessarily have to take courses over a long period; they can be done after school hours for an hour or two, every week. In Israel, there are two periodical types of pedagogical in-service training. The first is a semester course that of 30 hours, while the second is an annual course that takes 60 hours. During training, the teacher stays updated with practical and theoretical material from the Ministry of Education.

As mentioned above, the purpose of in-service training courses is to update the knowledge and professional development. Accordingly, the question that the study investigates is can these courses affect novice teachers' professional development. Novice or new teachers are doing or starting something for the first time; they can be new teachers teaching in a school or even teaching a new subject after obtaining a secondary teaching degree for the new subject [5].

Novice teachers take mandatory intern practice courses called Stag. They have to take them while teaching in an educational institution in their first year. During Stag courses, the teacher goes over theoretical and simulations on how to deal with certain issues that appears inside of a class. It can be related to classroom management or pedagogical content knowledge.

The researchers also seek to draw attention to the issue that investigates the effectiveness of in-service courses on novice teachers. In addition, it aims to examine the topics and areas that may interest the teachers under investigation.

Few studies have been conducted to examine the effect of in-service courses on a teacher's professional development. Moreover, no research was conducted to test the effect of in-service training courses on novice teacher professional development in Israel. Therefore, the current research tries to examine the effect.

\section{Literature Review}

In this section, the researchers will review professional development for novice teachers according to multiple scholars for advantages and disadvantages of these courses [5], [15]. In addition, the definitions and different point of views concerning these courses will be presented in this chapter. 


\section{Professional Development}

Professional development for teachers is a broad term that includes a variety of aspects connected to a teachers' professional and personal development [8]. The teacher's activity on professional development is a systematically organized, expedient and continuous process of developing professional and personal qualities that provide a socially set level of teacher's readiness for professional self-realization, through self-determination, self-education and self-discipline. The activity of professional development is characterized as socio-pedagogical. It functions and develops on the basis of its inherent features and conditions of implementation [3].

\section{In-Service Education}

In-service education can be described as the appropriate courses and activities in which a teacher can be engaged in order to develop his or her professional skills, expertise, and interests in the teaching profession. Thus, in-service education refers to the programs and classes that practicing instructors will participate in after completing initial instruction in order to further their professional development. In this case, in-service education meant to fill the gap between a serving teacher's professional inadequacies [11].

Furthermore, [4] cited that in-service training serves an essential role in teacher's professional development as it aids: (1) in the successful education reform; (2) a bridge between aspiring and experienced teachers to meet new challenges guiding students to higher learning and self-development; (3) In-service training should not be separated from the change that occurs because of teachers' professional development.

According to [4] in-service training is defined as the developments in the art of teaching and learning sparked by in-service training for teachers. Teachers have to remain updated on the most current ideas, thought, and study in their careers, as well as to be encouraged to carry on with professional development, in order to provide students with excellent and effective teaching and learning experiences.

\section{Types of In-service training}

In the opinion of [11], most teachers found today that they have nothing to offer by professional training, thus in-service training needs to be presented in order to update the teacher's knowledge, skills and competence. In-service training has several varieties according to [2]:
- Institutes: a series of lectures intended to deliver as much knowledge as possible to learners in a brief amount of time, typically two or three days. On another note, [10] described lectures as a regular course undertaking during the regular school year.

- Conferences: it encourages delegates to ask questions to one another and explore the ideas raised. On the other hand, [10] cited those conferences are academic events where a guest speaker is invited or charged to open a debate about a reasonably, necessary or contentious subject. Attendees come to the conference to listen, challenge the lead speakers, contribute to their own planned or random contributions, analyze views and points of view, and debate formally and informally among themselves.

- Workshops: a moderately sized group in which each individual has a problem to solve that is closely connected to his profession (a professional consultant leads each group). From the point of view of workshops, they can be thought of as educational events. However, in this case, they are specifically aimed at delivering selected practical interactions that will boost participants' job performance beyond their analytical horizons. Therefore, person or group task assignments differentiate workshops. Usually, resource persons are invited. They are those who are trained and provide participants with working procedures [10].

\section{Following the above varieties, (Maduabum, 1992) also provided an additional three varieties to in- service training types such as:}

- Seminars: A seminar is an academic forum where the main emphasis is on reflection or debate. It is led by a coordinator responsible for writing down a precise or brief description of the member within the discussion panel's points of view. Then, to facilitate full participation, the coordinator presents the highlights of the views shared at the end of the session and welcomes questions, feedback, suggestions, or contributions from the audience.

- Correspondence courses: There is no physical interaction between the instructor and the student in this form of in-service instruction. The term correspondence education comes from the fact that teachers and students communicate through the post.

- Exhibitions: These physical exhibits of scientific interest are meant to inform a broader scientific audience. They may be used in the classroom or in a wider sense to resolve social concerns, such as producing soap or dyes from local resources. 


\section{A Novice Teacher}

[15] defined novice as a person who has only recently begun to learn or do something. [5] gave an outstanding definition for a novice teacher. He defined it as those who have completed their language teacher preparation curriculum (which requires teaching practice) and have begun teaching English in an educational institution.

Furthermore, a teacher who enters a new cultural context can be considered a novice. [5] sees that a novice teacher ceases to be a novice after three years of teaching. [6] and [7] refers to this duration as the "career entry years."

[5] defined a novice teacher as teachers that have little or no previous classroom experience and are in their first year of teaching. Unless their principal exempts them, novices have to enroll in the Induction and Mentoring Program. Novices meet with their mentor(s) once a week to review lesson plans, administration, and teaching, etc. They prepare for their mentor(s) to watch and provide confidential guidance during teaching episodes. They also take replacement days to observe experienced teachers in other classes. That can also be seen in the educational system in Israel as it shares a similar approach for novice teachers.

\section{Previous Researches that Examined the Effectiveness of in-service Training on Teacher's Development}

Student learning and preparation for $21^{\text {st }}$ century skills require in-depth and ongoing professionalization of teachers from the entry stage of teaching through the course of training, internship and throughout the teaching career. Given that, such learning is done over time while allocating many resources. It has to be effective and leads to results that it seeks to promote, especially to improve teaching practices, teacher knowledge, and student achievement [14].

Data from across Israel were collected through telephone interviews and self-reporting. These data showed that only $70 \%$ of Hebrew-speaking teachers indicated that they had acquired professional feedback tools and they were prepared to serve as facilitators in the community [12]. It can be seen that $70 \%$ of Hebrew-speaking teachers had taken courses that enhances their professional development.

[1] conducted research that aimed to examine multiple questions about: (1) the effectiveness of performed in-service training programs and teachers' demonstration skills; (2) the effectiveness of performed in-service training programs and teachers after teaching (students' evaluation) skills. The research 5 questions, only 2 out of the 5 questions related to the occurring research. The population study is 150 heterogeneous guidance-school teachers who were randomly selected from four educational districts. The population consisted of different job experiences ranging from one to 26 years of experience and more. Their study showed that there is no effect for teaching skill development, or on teachers' demonstration skills.

[13] conducted a study to investigate the effect of in-service training. The research examined the level of teachers' professional development and performance. The findings show that in-service training/workshops were predictive factors, which had the greater significant effect on teacher performance. Their research's sample was consisting of 126 teachers across 26 primary schools.

Local research was conducted in Israel that assessed in-service training programs, and it was conducted by [9]. The research population consisted of 19 teachers in a mixed design approach to analyze the data. The research tools were a set of open-ended questions and close-ended questionnaires. The study was set on a two-year in-service training program. The finding presented at the end of the first year of the training show that the participants' perceptions of their ability to learn and teach mathematics have improved somewhat but not significantly. At the end of the in-service training program, the teachers were asked to complete a questionnaire to see if their pedagogical knowledge has changed because of the program, and there was an apparent increase in the teachers' pedagogical knowledge.

[1] research showed that there is no effect on teaching skill development, or on teachers' demonstration skills. Nevertheless, the research that was conducted by [9] showed an improvement in teacher's professional development; although it wasn not significant. However, the research that was conducted by [13] showed a remarkable improvement in teacher's development. The data of the researches conducted by the above researchers contradict each other, and because of that more research are needed to examine the effect of inservice training on teacher's professional development.

This study investigates the effect of pedagogical in-service training courses on novice teachers' professional development. The researcher believes that the literature presented in this section can help investigate the findings data and have comparable data.

\section{Question of the Study:}

To what extent do the in-service training courses for novice teachers increase their professional development in social interaction in school, classroom management, self-esteem, and educational knowledge? 


\section{Methodology}

\section{Instruments}

The researcher conducted a mixed-design approach consisting of a quantitative instrument (an online questionnaire) and a qualitative instrument (open ended questions). The quantitative instrument was sent to random novice teachers (1-3 years of experience). The questionnaire is designed according to Likert's five answers scale, and it focused on the following dimensions: (1) Social interaction in school; (2) Educational knowledge; (3) Self-esteem; (4) Classroom Management. In addition, the qualitative instrument was given to the participants within the questionnaire, which focused on the needs of the participants in in-service courses. The qualitative data were divided into the previously mentioned quantitative dimensions.

\section{The validity of the Instrument}

The researchers established the validity of the research instruments by presenting them to some expert lecturers from academic college for teacher education, and their comments were taken into consideration. The construction validity was checked by calculating the Pearson correlation coefficient. It was found through the results that the tool has a construct validity ranging between $\left(.556^{* *}\right)$ and $(.922 * *)$.

In order to understand the teachers' perception of in-service training courses, the findings were categorized into four dimensions: social interaction in school, self-esteem, classroom management, and educational knowledge.

\section{Reliability of the Instrument}

The stability of the instrument was checked according to the Alpha Cronbach coefficient, and the results were as shown in Table 1.

Table 1. Alpha Cronbach of the questionnaire

\begin{tabular}{|lcc||}
\hline \multicolumn{1}{|c}{ Category } & Alpha Cronbach & Number of items \\
Social interaction in school & .835 & 3 \\
Educational knowledge & .816 & 4 \\
Self-esteem & .853 & 4 \\
Classroom management & .829 & 4 \\
All categories combined & .946 & 15 \\
\hline
\end{tabular}

Table 2 shows the questionnaire items. 15 questions that constitute the questionnaire are listed in order in this Table.

Table 2. Questionnaire items

Questionnaire items

1. In-service training helped my professional interaction with parents as a new teacher.

2. In-service training improved my professional development in teaching through ICT.

3. Professional development courses improve my ability to deal with the different situations.

4. Participating in capacity development workshops helps my management skills.

5. In-service training helped me with staff interaction in school.

6. Having lectures from pedagogical educators has helped my educational knowledge.

7. Professional development courses improve my self-esteem to coordinate my plans.

8. Having staff meeting helps with to understand to coordinate a better plan through hearing about different staff plans.

9. In-service broke the barrier of a new teacher and the school management.

10. Having lectures from pedagogical educators has helped me make better classroom decisions.

11. Professional development courses improve my self-esteem with verbal persuasions.

12. Workshops improve my classroom management skills.

13. The capabilities of in-service courses help in delivering material for students through the modern curriculum.

14. In my opinion, the participation of new teachers in manual workshops aimed at developing the educational capabilities of new teachers is important.

15. In-service helps in addressing emergency educational issues in educational frameworks. 
Table 3 shows the open-ended questions items. This section is composed of two major questions in which the research participants are the addressees.

Table 3. open-ended questions items

1. What are the three most needed in-service training courses that you need?

2. What are the additional pedagogical needs that you need?

\section{Research Findings}

The study used a questionnaire to collect empirical data and draw the study results for the quantitative questions. The questionnaire consists of Likert's five answers scale - from strongly disagree to strongly agree. The participants' collected responses ranged from one to five. With one being strongly disagree, and five being strongly agreed.
As for the qualitative questions, the researcher used the data from the interviews to draw a broader conclusion. The following Table shows the descriptive findings about the participants of the study.

Table 4 thoroughly exhibits the statistical data relating the research participants.

Table 4. Statistical findings of the participants of the research

\begin{tabular}{|c|c|c|c|}
\hline \multicolumn{2}{|c|}{ Variables } & Frequency & Percent \\
\hline \multirow{3}{*}{ Gender } & Male & 13 & 43.3 \\
\hline & Female & 17 & 56.7 \\
\hline & 1 & 7 & 23.3 \\
\hline \multirow[t]{2}{*}{ Experience } & 2 & 11 & 36.7 \\
\hline & 3 & 12 & 40 \\
\hline \multirow{3}{*}{ School } & Junior - High & 11 & 36.7 \\
\hline & High School & 19 & 63.3 \\
\hline & B.A. & 3 & 10.0 \\
\hline \multirow[t]{2}{*}{ Degree } & M.A. & 19 & 63.3 \\
\hline & B. Ed. & 8 & 26.7 \\
\hline \multirow{2}{*}{ Diploma in education } & Yes & 30 & 100 \\
\hline & No & 0 & 0 \\
\hline \multirow{2}{*}{ Finished stag } & Yes & 30 & 100 \\
\hline & No & 0 & 0 \\
\hline Where do you teach? & South & 30 & 100 \\
\hline
\end{tabular}

Table 4 shows that the research participants are all Arab teachers from the South Sector of Israel and that they all have got their educational diploma and the stag course. The participants were of both genders (female and male) all up to 30, the frequency of the males is $13(43.3 \%)$, and $17(56.7 \%)$ for the females. As for the experience, the participants' experience ranged from 1 to 3 years, $7(23.3 \%)$ participants had one year of experience, $11(36,7 \%)$ participants had two years of experience, and 12 (40\%) participants three years of experience. For the school section, Junior-High teachers are 11 (36.7\%), and High school English teachers are 19 (63.3\%). In regards to the educational degrees, the participants were 3 (10\%) B.A., 8 (26.7\%) B.Ed. and 19 (63.3\%) M. A degree holders.
To what extent do the in-service training courses for novice teachers increase their professional development in social interaction in school, classroom management, self-esteem, and educational knowledge?

In order to answer the above research question, data analysis through SPSS was conducted. The following Tables have statistical data for each dimension and analysis for all the data. As previously mentioned, the questionnaire used Likert's five answers scale, and thus a median of 3 is set as the test value (3 equals neutral). The data was collected through one sample T-test.

Table 5 shows the means, and standard deviations of the social interaction in school. 
Table 5. Means, and Standard Deviations of the social interaction at school

\begin{tabular}{|cccc||}
\hline Items & Mean & S.D & Tendency: Positive or Negative \\
1 & 3.3333 & 1.24106 & Positive \\
2 & 3.7000 & 1.36836 & Positive \\
3 & 3.6667 & 1.15470 & Positive \\
Overall mean & 3.566 & 1.09 & \\
\hline
\end{tabular}

Table 6 represents the participants' responses toward the social interaction in school dimension.

Table 6. Social Interaction in school responses

Dimension

Seven of the participants expressed a positive attitude towards the dimension, social interaction in school. They also supported their opinion in noting the types of courses that could benefit them to develop their professional development. Below are quotes from the respondents.

"As a new teacher, any pedagogical needs that focus on social interaction between the new teacher and school/students/parents are what's important. Also, Workshops, Staff meetings, and Simulation"

(Respondent 1)

"Dealing with special needs students" (Respondent 2)

"Teaching in heterogeneous classes" (Respondent 3)

"Community and cultural championing and support" (Respondent 4)

"Teaching in heterogeneous classes" (Respondent 5)

"Courses that enhance pedagogical elements" (Respondent 13)

"Practical more than lecturing, gives examples from the experience of professional teachers who has been teaching for so long are more of a help than today's new teachers giving the in-service courses, and more thematic, not wide branched and it must be deducted for a whole year of learning and training in order to be able to reach the goal set" (Respondent 14)

Table 7 shows the means and standard deviation of the social interaction category towards in-service training courses. As seen from the Table, the respondents' mean is 3.566, with a standard deviation of 1.09. As such, the mean difference of the social interaction in school dimension is more significant than the test value. Moreover, in Table 7, the frequency analysis of the open-ended questions showed that $47 \%$ of the participants favor taking social interaction in school courses over other courses. Furthermore, due to the above results, one can understand that the direction of social interaction in school for in-service training courses is positive since the mean is higher than the neutral value (test value 3 = neutral).

The following Table shows the Means, and Standard Deviations of Educational Knowledge.

Table 7. Means and Standard Deviations of Educational Knowledge

\begin{tabular}{|c|c|c|c|}
\hline Items & Mean & $\begin{array}{l}\text { Standard } \\
\text { deviation }\end{array}$ & Tendency \\
\hline In-service training improved my professional development in teaching through ICT. & 3.6667 & 1.26854 & Positive \\
\hline Having lectures from pedagogical educators has helped my educational knowledge. & 3.8667 & 1.16658 & Positive \\
\hline $\begin{array}{l}\text { Having lectures from pedagogical educators has helped me make better classroom } \\
\text { decisions. }\end{array}$ & 4.0000 & .78784 & Positive \\
\hline $\begin{array}{l}\text { The capabilities of in-service courses help in delivering material for students } \\
\text { through the modern curriculum. }\end{array}$ & 3.8333 & .98553 & Positive \\
\hline Mean for all the questions & 3.841 & .857 & \\
\hline
\end{tabular}


Table 8 represents the participants' responses toward the educational knowledge dimension.

Table 8. Educational Knowledge responses

\begin{tabular}{||ll||}
\hline \hline Dimensio & Participants' responses \\
& Seven of the participants expressed a positive attitude towards the dimension, Educational Knowledge. \\
They also supported their opinion in noting the types of courses that could benefit them to develop their \\
professional development. Below are quotes from the respondents. \\
"Microsoft Teams Work, Teaching Literature, and More digital tools for using in classroom” \\
(Respondent 2) \\
"Digital Education Tools, New Techno-pedagogical tools, Teaching from distance” (Respondent 3) \\
"Technology that helps students learn" (Respondent 4) \\
"Oral, writing, and reading skills" \\
(Respondent 5) \\
"Digital Education Tools, and Teaching from distance” (Respondent 7) \\
"Technical training, safety training, Skills training” (Respondent 8) \\
"Skills training”(Respondent 15)
\end{tabular}

Table 8 shows the means and standard deviation of the educational knowledge category towards inservice training courses. As seen from the Table, respondents' mean is 3.841, with a standard deviation of 8.57. As such, the mean difference of the educational knowledge category is more significant than the test value. Moreover, in Table 9, the frequency analysis of the open-ended questions

Table 9. Means, and Standard Deviations of self-esteem showed that $47 \%$ of the participants favor taking educational knowledge courses over other courses. Furthermore, due to the above results, one can assume that the direction of education knowledge for in-service training courses is positive since the mean is higher than the neutral value (test value $3=$ neutral).

Table 9 shows the Means, and Standard Deviations of self-esteem among the research participants.

\begin{tabular}{|c|c|c|c|}
\hline Items & Mean & $\begin{array}{l}\text { Standard } \\
\text { deviation }\end{array}$ & Tendency \\
\hline $\begin{array}{l}\text { Professional development courses improve my ability to deal with the different } \\
\text { situations. }\end{array}$ & 3.7333 & 1.28475 & Positive \\
\hline $\begin{array}{l}\text { Professional development courses improve my self-esteem to coordinate my } \\
\text { plans. }\end{array}$ & 3.6333 & 1.24522 & Positive \\
\hline $\begin{array}{l}\text { Professional development courses improve my self-esteem with verbal } \\
\text { persuasions. }\end{array}$ & 3.5333 & 1.04166 & Positive \\
\hline $\begin{array}{l}\text { In my opinion, the participation of new teachers in manual workshops aimed at } \\
\text { developing the educational capabilities of new teachers is important. }\end{array}$ & 4.1000 & .92289 & Positive \\
\hline Mean for all the questions & 3.75 & .945 & \\
\hline
\end{tabular}

Table 10 represents the participants' responses toward the educational knowledge dimension.

Table 10. Self-esteem responses

\begin{tabular}{||ll||}
\hline Dimension & $\begin{array}{l}\text { Participants' responses } \\
\text { Seven of the participants expressed a positive attitude towards the dimension, Self-esteem. They also }\end{array}$ \\
Self-esteem & $\begin{array}{l}\text { supported their opinion in noting the types of courses that could benefit them to develop their } \\
\text { professional development. Below are quotes from the respondents. } \\
\text { "Improve my performance and increase productivity" (Respondent 9) }\end{array}$ \\
\hline
\end{tabular}

As noted by Table 10, the means and standard deviation of the self-esteem category towards inservice training courses are presented. As seen from the Table, the respondents' mean is 3.75 , with a standard deviation of .945 . As such, the mean difference of the self-esteem category is more significant than the test value. Moreover, in Table 11, the frequency analysis of the open-ended questions showed that $6.667 \%$ of the participants favor taking self-esteem courses over other courses. Furthermore, due to the above results, one can get the impression that the direction of self-esteem for in-service training courses is positive since the mean is higher than the neutral value (test value $3=$ neutral). Therefore, even if the teachers did not point out the use of self-esteem in the open-ended questions, it could be viewed as an essential dimension for teacher's professional development. 
Table 11 shows the Means, and Standard management. Deviations of the fourth category of classroom

Table 11. Means, and Standard Deviations of classroom management

\begin{tabular}{|lccc||}
\hline \multicolumn{1}{|c}{ Items } & Mean & $\begin{array}{c}\text { Standard } \\
\text { deviation }\end{array}$ & Tendency \\
$\begin{array}{l}\text { Participating in capacity development workshops helps my } \\
\text { management skills. }\end{array}$ & 3.7333 & 1.22990 & Positive \\
$\begin{array}{l}\text { Havingstaffmeetinghelpswithtounderstand tocoordinateabetter } \\
\text { plan through hearing about different staff plans. }\end{array}$ & 4.2333 & 1.00630 & Positive \\
$\begin{array}{l}\text { Workshops improve my classroom management skills. } \\
\text { In-servicehelpsinaddressing emergency educational issuesin }\end{array}$ & 3.9333 & .98027 & Positive \\
educational frameworks. & 4.1000 & .84486 & Positive \\
All the above items. & 4 & .84 & \\
\hline \hline
\end{tabular}

Table 12 represents the participants' responses toward the classroom management in school dimension.

Table 12. Classroom management responses

\section{Dimension Participants' responses}

Seven of the participants expressed a positive attitude towards the dimension, Classroom management. They also supported their opinion in noting the types of courses that could benefit them to develop their professional development. Below are quotes from the respondents.

Table 13 shows the means and standard deviation of the classroom management category towards inservice training courses. As seen from the Table, the respondents' mean is 4 , with a standard deviation of .84. As such, the mean difference of the classroom management category is more significant than the test value. Moreover, in Table 13, the frequency analysis of the open-ended questions showed that
$30 \%$ of the participants prefer taking classroom management courses to other courses. Furthermore, due to the above results, one can get the impression that the direction of classroom management for inservice training courses is positive since the mean is higher than the neutral value (test value 3 = neutral).

Table 13 shows the statistical data for research categories.

Table 13. Statistical data for the categories' averages

\begin{tabular}{|lcccccc||}
\hline Category & $\mathrm{N}$ & Mean & $\mathrm{SD}$ & $\mathrm{T}$ & $\mathrm{Df}$ & $\mathrm{Sig}$. \\
Social interaction in school & 30 & 3.566 & 1.09 & 2.847 & 29 & .008 \\
Educational knowledge & 30 & 3.841 & .857 & 5.378 & 29 & .000 \\
Self-esteem & 30 & 3.75 & .945 & 4.349 & 29 & .000 \\
Classroom management & 30 & 4 & .833 & 6.575 & 29 & .000 \\
Overall data & 30 & 3.804 & .84 & 5.244 & 29 & .000 \\
\hline
\end{tabular}

An overall test was conducted to view four categories as a whole. It is seen from the above Table that the mean difference is 3.8 , which is more significant than the test value (3). Furthermore, it can be seen from the Table that the statistical significance (sig.) is .00, which means that it is less than .05 . Therefore, the researcher concludes with the help of
SPSS that there is a significant difference in the effect averages for four categories.

Figure 1 shows means, standard deviations, and significance probability of the four categories addressed by the research. 


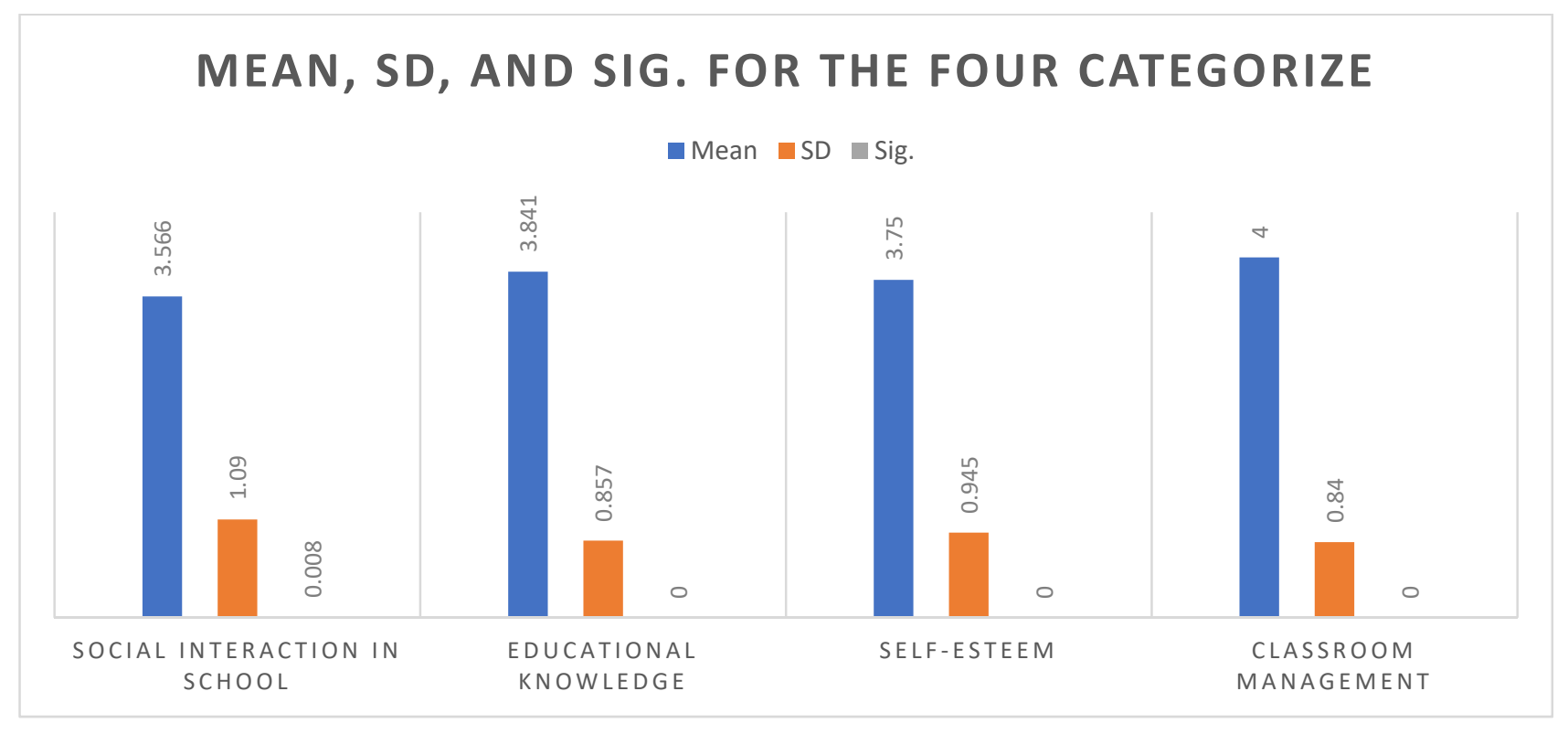

Figure 1. SD and Sig. for the four categories

Figure 1 shows the Mean, SD, and Sig. for four categories; by looking at the elements of the diagram, it can be seen that the mean of the social interaction is the lowest out of the four categories (3.566). Moreover, the classroom management category is the highest out of the four categories at a mean difference of 4 .

\section{Discussions}

In this section, the researchers discuss the results from the research findings. In addition, the result of the study will be compared with the results of the previously mentioned studies reviewed in the literature section.

The study aims to examine the impact of pedagogical in-service training courses on novice teachers' professional development. Moreover, it aims to find out the types of in-service courses novice teachers should consider taking to develop their professional development.

The current study investigates the influence of pedagogical in-service training courses on novice teacher's professional development. Beginning with the first dimension social interaction, the results showed a higher than neutral value, a positive result. In addition, social interaction significantly influences teachers' professional development, as is emphasized in the open-ended questions of the survey. Fortyseven per cent of respondents said they needed social interaction in school courses in order to develop their profession.

When taking social interaction in school courses, a novice teacher will develop his profession in order to deal with problems that occur in school. For example, when students argue with themselves, which leads to a fight or cursing, the teacher would end the conflict quickly and with no trouble. In addition, the teacher would know the ethical limitation between a teacher and students, especially if the teacher is new and that he is in a new culture.

Secondly, regarding the category of the educational knowledge, the results show a higher than neutral value, a positive result. In addition, educational knowledge courses significantly influence teachers' professional development, as is emphasized in the open-ended questions of the survey. Forty-seven per cent of respondents said they needed educational knowledge courses the most in order to develop their professional development. Given that it is nearly half of the participants, it is considered significantly high.

Thirdly, regarding the self-esteem category, the results showed a higher than neutral value, a positive result. It can also be noted that the open-ended questions of the questionnaire have a contradiction in the results as less than ten per cent of the participants showed an interest in self-esteem. Therefore, the results showed a high gap between the open-ended questions which can be seen as a negative result, and the questionnaire results ( 3.75 mean), which can be seen as a positive result (test value $=3$ ). It can be elaborated through the co-teaching programs presented to the teachers in their beginning years of teaching. The program is called Stag courses, and they are mandatory. Moreover, the researcher mentions one or two points out that self-esteem is essential for the professional development of novice teachers.

An important research was conducted by [9] that analysed pedagogical knowledge over two years. It showed an increase in teachers' self-efficacy and personal commitment to teaching and raising students' achievement levels. This data is similar to the above self-esteem category. In addition, selfesteem courses may embody the teacher to have the 
ability to dominate the class without scolding the students, deliver information smoothly, and interact with students socially among themselves to create a class social environment.

Finally, regarding the extent of pedagogical inservice training courses affecting a novice teacher's classroom management, the results showed a significant effect higher than the neutral value, a positive result. In addition, classroom management courses have a significant impact on teacher professional development, as is emphasized in the open-ended questions of the study. Thirty per cent of respondents said they needed Classroom Management courses. This data is highly considering, and that it is around the third of the participants.

The present study contradicts [1] research. Their results showed no significant differences in the effect averages for lesson plan preparation towards inservice training courses from the point of view of teachers. In contrast, the present study showed a significant difference in the effect mean averages towards the classroom management, which contains material management and lesson preparations (lesson plan, unit plan and annual plan).

The above results from the participants' responses to the questionnaire, question whether novice teachers require training in educational knowledge and social interaction the most. Both Educational Knowledge and Social Interaction in school categories share the same responses from the participants $(47 \%)$.

The research that was conducted by [13] showed similar results towards in-service training, as it showed to be a predictive factor to teacher's professional development. The collected data showed that social interaction in school, classroom management, self-esteem, and educational knowledge would play a significant role in the professional development of novice teachers.

\section{Conclusions and Recommendations}

Classroom Management is an essential factor and has a significant effect on the professional development of the participants. Thus, by taking pedagogical training courses in classroom management, teachers will improve their ability to control their classes, will be able to manage and prepare their lessons with updated material and methods, and strengthen the ability to be leaders.

By taking pedagogical training courses in educational knowledge, teachers will improve and develop their abilities to acquire new and relevant knowledge, such as using modern technologies by keeping pace with modernity and language skills.
The Self-esteem dimension is also very important for teacher development. It was concluded that selfesteem dimension has a positive effect on teachers' professional development. Teachers will be more confident after taking these courses. Furthermore, self-esteem may enhance dominance, decisionmaking, and classroom management.

Finally, the researchers advise novice teachers to prioritize their needs in social interaction and educational knowledge courses in order to develop steadily. Novice teachers should take an annual course for two to three years. English coordinators of ELT should care for the teachers to make sure that they participate in these courses, because they help teachers to cope with all kinds of problems they may tackle in the school. The researchers also recommend taking courses in classroom management and courses related to the development of self-esteem at least one course in the first two years.

Further study needs to explore the effect of inservice training courses on veteran teachers' professional development and compare the data between the two studies. Another study could be conducted to check the effect of these courses on other dimensions of teachers' development, such as presentation and appreciation of culture and literature.

\section{References}

[1]. Ahmadi, S., \& Keshavarzi, A. (2013). A survey of inservice training programs effectiveness in teaching skills development from the view-point of students, teachers and principals of guidance schools in Shiraz. Procedia-social and Behavioral sciences, 83, 920-925.

[2]. Asaya, S. A. (1991). In-service education of teachers: Problems and prospects. In A Paper Presented at a Conference on teacher Education Organized by the Lagos State College of Education. Oto-Ijanikin, 10th14th February.

[3]. Burkhanova, I. Y., Akmambetova, M. E., SavelevaRath, E. A., Ivanova, S. S., Stafeeva, A. V., Vorobyov, N. B., \& Ignatyeva, E. V. (2020). Metaeducational design as a technology of professional development of teachers. Journal of Environmental Treatment Techniques, 8(1), 235-240.

[4]. Omar, C. M. Z. C. (2014). The need for in-service training for teachers and its effectiveness in school. International Journal for Innovation Education and Research, 2(11), 1-9.

[5]. Farrell, T. S. (2012). Novice-service language teacher development: Bridging the gap between preservice and in-service education and development. Tesol Quarterly, 46(3), 435-449.

[6]. Huberman, M. (1989). The professional life cycle of teachers. Teachers college record, 91(1), 31-57.

[7]. Huberman, M. (1993). The lives of teachers. Teachers College Press. 
[8]. Igawa, K. (2002). The effects of in-service training on teachers' explanation of lexical items in Japanese high school classrooms. Temple University.

[9]. Levy-Keren, M. (2014). Assessment of the program: "Teachers initiating and implementing educational programs" for mathematics teachers at elementary and junior high schools within the framework of professional development for educational practitioners. Final Report. Tel Aviv: Kibbutzim College of Education, Research and Assessment Unit.

[10]. Maduabum, M. A. (1992). issues in in-service education of science teachers in Nigeria in Afe. Inservice education of teachers: the Nigerian experience, Asaba, JID Printers (Nig.) Ltd.

[11]. Osamwonyi, E. F. (2016). In-Service Education of Teachers: Overview, Problems and the Way Forward. Journal of Education and Practice, 7(26), 83-87.
[12]. Ratner, D'. (2018). Evaluating Leading Teachers A Viewpoint. 1-78. [in: Hebrew].

[13]. Sonam, K., \& Niramitchainont, P. (2020, April). Effects of Teachers' Professional Development on Teacher Performance in Primary schools of Chhukha district, Bhutan. In The 2nd China-ASEAN International Conference 2020 \& The 2nd International Conference on Tourism, Business, \& Social Sciences 2020: Insight to China and ASEAN's Wellness, Tourism, \& Innovation (pp. 477-489). Dhurakij Pundit University. doi:10.6947/caicictbs.202004.0044

[14]. Sperling, D'. (2018). Effectiveness of professional development. 1-47 [Hebrew]. Retrieved from: http://education.academy.ac.il/SystemFiles/23227.pdf [accessed: 10 August 2021].

[15]. Webster, M. (2021, July). Novice. Retrieved from: https://www.merriam-webster.com/dictionary/novice [accessed: 10 August 2021]. 